\title{
Nontumorous Enlargement of the Internal Auditory Canal: A Risk Factor for Sensorineural Hearing Loss? A High Resolution CT-Study
}

\section{Weit angelegter innerer Gehörgang: Ein Risikofaktor für Schwerhörigkeit? Eine HR-CT-Studie}

Authors

Affiliations
H. Stimmer ${ }^{1}$, H. P. Niedermeyer ${ }^{2}$, V. Kehl ${ }^{3}$, E. J. Rummeny ${ }^{4}$

Department of Radiology, Klinikum rechts der Isar Technical University Munich, Germany

ENT-Clinic, Klinikum rechts der Isar, Technical University Munich, 81675 Munich, Germany

Institute for medical Statistics and Epidemiology, Klinikum rechts der Isar, Technical University Munich, 81675 Munich, Germany

${ }^{4}$ Department of Radiology, Klinikum rechts der Isar, Technical University Munich, 81675 Munich, Germany
Key words

$\checkmark$ head/neck

- CT

- hearing loss

inner ear

perilymph received 24.10.2014

accepted $\quad$ 4.1.2015

Bibliography

Dol http://dx.doi.org/

10.1055/s-0034-1399009

Published online: 23.4.2015

Fortschr Röntgenstr 2015; 187 :

450-458 @ Georg Thieme

Verlag KG Stuttgart - New York .

ISSN 1438-9029

\section{Correspondence}

\section{Dr. Herbert Stimmer}

Institut für Röntgendiagnostik, Klinikum rechts der Isar TU

München

Ismaningertsr.22

81675 München

Germany

Tel.: ++ 49/0 89/41405605

Fax: ++ 49/0 89/41404834

stimmer@roe.med.

tu-muenchen.de

\section{Zusammenfassung}

$\nabla$

Ziel: Erstes Anliegen der Studie war es die normale Form und Größe des inneren Gehörganges (IAC) auf CT-Basis zu definieren. Im zweiten Teil sollte die klinische Relevanz einer Erweiterung des inneren Gehörganges untersucht werden, wobei insbesondere auch begleitende Läsionen am Fundus des inneren Gehörganges bzw. am angrenzenden Innenohr berücksichtigt werden sollten.

Material und Methoden: 440 HR-CT's des Felsenbeins wurden retrospektiv unter besonderer Berücksichtigung des inneren Gehörganges und dessen Fundus-Region ausgewertet.

Ergebnisse: Der CT-basierte Mittelwert des IACDurchmessers in axialer und koronarer Ebene wurde bestimmt, in 20 von 440 Fällen zeigte sich eine Erweiterung. In der Gruppe mit ausgeprägter Erweiterung (3-fache SD) zeigten nahezu alle Patienten eine Hörminderung. Einige hiervon wiesen Auffälligkeiten der knöchernen Struktur in der Region des IAC-Fundus an der Grenzzone Liquor/Perilymphe auf.

Schlussfolgerung: Die Untersuchung erlaubt eine neue CT-basierte Definition des normalen IACDurchmessers sowie auch von dessen Form. Zudem erbringt die Studie Hinweise auf eine pathophysiologische Bedeutung der Übertragung von Liquordruck auf das Innenohr bei erweitertem inneren Gehörgang oder angrenzenden Fistelverbindungen in der Entwicklung einer Schwerhörigkeit.

Kernaussagen:

- Neue CT-basierte Definition der normalen Form und Größe des inneren Gehörganges.

- Nahezu alle Patienten mit stark erweitertem inneren Gehörgang zeigen Hörverlust.

- Knöcherne Defekte begünstigen pathologische Liquordruckübertragung auf das Innenohr.

\section{Abstract \\ $\nabla$}

Purpose: First aim of the study was to define normal shape and diameter of the internal auditory canal (IAC). In the second part the clinical relevance of IAC-enlargement was analyzed, considering also lesions of the subtle structures at the fundus of the internal auditory canal.

Materials and Methods: 440 high resolution CTscans of the temporal bone were used for retrospective analysis of the internal auditory canal and its fundus region.

Results: The mean value of the IAC diameter in axial and coronal plane was determined. In 20 of 440 patients IAC enlargement was found. In the group with pronounced enlargement (3fold SD) nearly all patients suffered from hearing impairment. In some of them we found structural abnormalities near the IAC fundus in the CSF/perilymph border zone.

Conclusion: A new CT-based definition of normal shape and diameter of the internal auditory canal is presented. There is some evidence that a pathologic transmission of CSF-pressure in case of IACenlargement and/or abnormal fistulous communications could play an important role in the pathophysilogy of hearing loss.

Key points:

- New CT-based definition of normal internal auditory canal.

- Nearly all patients showing pronounced IACenlargement suffer from hearing impairment.

- Possible pathomechanism: Transmission of CSFpressure on the inner ear.

Citation Format:

- Stimmer H, Niedermeyer HP, Kehl V et al. Nontumorous Enlargement of the Internal Auditory Canal: A Risk Factor for Sensorineural Hearing Loss? A High Resolution CT-Study. Fortschr Röntgenstr 2015; 187: 450-458 


\section{Introduction}

\section{$\nabla$}

The internal auditory canal (IAC) is an important anatomic landmark in the posterior portion of the temporal bone. This bony canal allows the neural connection between the inner ear's receptors and the brainstem nuclei of the $8^{\text {th }}$ cranial nerve, the course of the facial nerve through the skull base and the blood supply of the inner ear via the labyrinthine artery.

The IAC contains the vestibulocochlear nerve, dividing into the cochlear, superior and inferior vestibular nerve, the facial nerve with its intermedius portion and the labyrinthine artery. The neural structures are coated by an arachnoid membrane and the IAC is lined by a dural sheet.

Already in the era of conventional X-ray tomography, the IAC was examined in detail. Valvassori described a cylindrical shape of the IAC with a constant diameter in the longitudinal axis in about $50 \%$ of all cases, an ovoid appearance with the greatest height in the middle part in about $25 \%$ of all cases and a wedge-shaped appearance in the remaining $25 \%$ of cases.

The IAC showed a variable diameter from 2 to $12 \mathrm{~mm}$ with an average diameter (in height) of $5 \mathrm{~mm}$. The interindividual variability in shape and diameter was substantial, but the intraindividual difference between both sides was not more than $1 \mathrm{~mm}$ in $95 \%$ of healthy persons.

The length of the IAC, defined as the distance between the vestibular labyrinth and the medial margin of the posterior wall, was also considerably variable. The average was $8 \mathrm{~mm}$ with a range from $4 \mathrm{~mm}$ to $15 \mathrm{~mm}$. In healthy persons the intraindividual difference between both sides was not more than $2 \mathrm{~mm}[1,2]$.

Stenosis of the IAC is a rare finding. The required diameter for the neurovascular bundle running through the internal auditory canal is about $2 \mathrm{~mm}$. Therefore, a stenosis of $2 \mathrm{~mm}$ or less is regarded as significant. [2].

Possible reasons for acquired uni- or bilateral IAC enlargement are tumors originating in the IAC such as uni- or bilateral acoustic neuroma or, much less commonly, advanced facial neuroma.

Acoustic neuromas are located only in the IAC in $20.7 \%$ of cases, in the IAC and cerebellopontine angle cistern in $73.9 \%$ of cases and exclusively in the cerebellopontine angle cistern in $5.4 \%$ of all cases. IAC enlargement was observed in $51.1 \%$ of acoustic neuromas [3].

Expansion into the labyrinthine structures is rare [4]. Tumorous IAC enlargement caused by acoustic neuroma is characterized by a smooth delineation of the IAC walls. A bony defect of the crista falciformis is typical. [5].

Some other space-occupying lesions and hereditary diseases also cause uni- or bilateral IAC enlargement. Unilateral IAC expansion was reported in a case of posterior fossa ependymoma growing in the internal auditory canal [6]. Another unusual reason for IAC enlargement is the intracanalicular manifestation of cavernomas as reported by Aquilina and Samii $[7,8]$.

Recently a case report was published presenting a patient with intrameatal manifestation of an arachnoid cyst causing hearing impairment and tinnitus [9]. Patients with von Recklinghausen neurofibromatosis show bilateral IAC enlargement not only in type 2 neurofibromatosis as a consequence of bilateral acoustic neuromas but also in type 1 neurofibromatosis without any tumorous lesion. The pathomechanism is unclear [10]. A variant of the IAC with a funnel-shaped appearance was described in the rare branchio-oto-renal syndrome [11] and bilateral enlargement of the IAC was found in Paget's disease [12]. In Down syndrome (Trisomia 21) IAC duplication was seen [13].
Literature focusing on dysplasia of the IAC is very limited. Weinberg postulated a developmental disorder of the temporal bone leading to IAC enlargement [14].

Kokai's 2003 publication on a CT-based analysis of inner ear malformation reports anomalies of the labyrinthine structures as most frequent and narrow IAC with an occurrence of $2 \%$ but no IAC enlargement [15]. Analyzing a large number of temporal bone CT scans (645 patients), Migirov found 2 patients with "patulous" IAC enlargement. He did not see any association with anomalies of the labyrinth [16].

Lack of information and inconsistent results in literature gave reason for a new study based on an extensive database from 64row multislice computed tomography. A current study that defines the IAC diameter based on multislice CT does not exist to the knowledge of the authors. The functional implications of IAC enlargement and related abnormalities in the IAC fundus are discussed below.

\section{Materials and methods \\ $\nabla$}

880 high-resolution CT scans (440 patients) of the temporal bone from 2005 to 2011 stored in our Philips PACS system were reevaluated. The sample in this retrospective study was drawn from an unselected group of patients of an ENT university department.

The different clinical indications for HR-CT are distributed as follows ( $\bullet$ Table 1 ).

Because of the large number of CT examinations and highly different clinical indications, this sample seemed to be suitable for statistical evaluation.

It is important to note that none of the patients had clinical or radiological signs of acoustic neuroma or other space-occupying lesions of the IAC or the cerebellopontine angle cistern.

Patient age was highly variable ranging from 1 to 96 years. The average age was 42.95 years.

All patients were examined with the same 64-row multislice CT scanner: Siemens Sensation Cardiac 64 (Siemens, Erlangen, Germany).

The examination technique was the same for every patient. We used a spiral CT mode with a rotation time of 1 second, a pitch of 0.9 and constant X-ray tube parameters with a collimation of $0.6 \mathrm{~mm}, 120 \mathrm{kV}$ tube voltage and $150 \mathrm{mAs}$. In all examinations axial and coronal reconstuctions were made with a reconstruction thickness of $1 \mathrm{~mm}$ without a reconstruction interval. Every IAC was evaluated in two perpendicular planes.

We compared our findings with the normal range of the IAC diameter, defined and published by Valvassori using conventional $\mathrm{X}$-ray tomography. Valvassori`s measurement of the IAC diameter

Table 1 Clinical indications for HR-CT.

\begin{tabular}{|c|c|}
\hline hearing loss (unclassified) & $41.0 \%$ \\
\hline inflammatory symptoms & $23.6 \%$ \\
\hline trauma & $12.0 \%$ \\
\hline cholesteatoma & $5.7 \%$ \\
\hline malformation & $5.2 \%$ \\
\hline neoplastic diseases & $5.0 \%$ \\
\hline vertigo & $5.0 \%$ \\
\hline tinnitus & $1.1 \%$ \\
\hline otosclerosis & $0.7 \%$ \\
\hline facial nerve paresis & $0.7 \%$ \\
\hline
\end{tabular}


refers to the altitude of the canal, measured bilateral in the same distance to the vestibular labyrinth $[1,17]$

In the present study the following measurement method was used:

The middle of the anterior and posterior wall and roof and floor of the IAC were chosen as a reference point for measurement. The diameter of the IAC in the axial and coronal plane was defined as the shortest connection line between these reference points.

Statistical analysis included calculation of the mean value and standard deviation, regression analysis, cross-table calculation and Bland-Altman diagrams.

In addition to IAC measurement and statistical analysis, the IAC borders and structure of the IAC fundus and also of the adjacent inner ear were carefully analyzed for bony defects or other morphologic abnormalities.

\section{Results and analysis}

$\nabla$

Considerable variability of the IAC diameter in the axial and coronal plane was observed. In the axial plane we found a diameter between 1.1 and $10.7 \mathrm{~mm}$, in the coronal plane between 1.4 and $8.8 \mathrm{~mm}$. In the coronal plane the variability was a little smaller than in the axial plane.

The mean value of the IAC diameter in the axial plane was $5.55 \mathrm{~mm}$ on the right and $5.56 \mathrm{~mm}$ on the left, and in the coronal plane $4.82 \mathrm{~mm}$ on the right and 4.87 on the left ( $\bullet$ Fig. $1 \mathbf{a}-\mathbf{d}$ ).

The standard deviation in the axial plane was 1.16 on the right and 1.11 on the left side, and in the coronal plane 0.97 on the right and 0.98 on the left.

This data demonstrates a high degree of intraindividual symmetry of shape and diameter of the IAC ( $\bullet$ Fig. 2a, b) as well as a high interindividual variability.

Based on the $95 \%$ confidence interval, we found the following normal range for IAC diameter in HR-CT ( $\bullet$ Table 2 ).
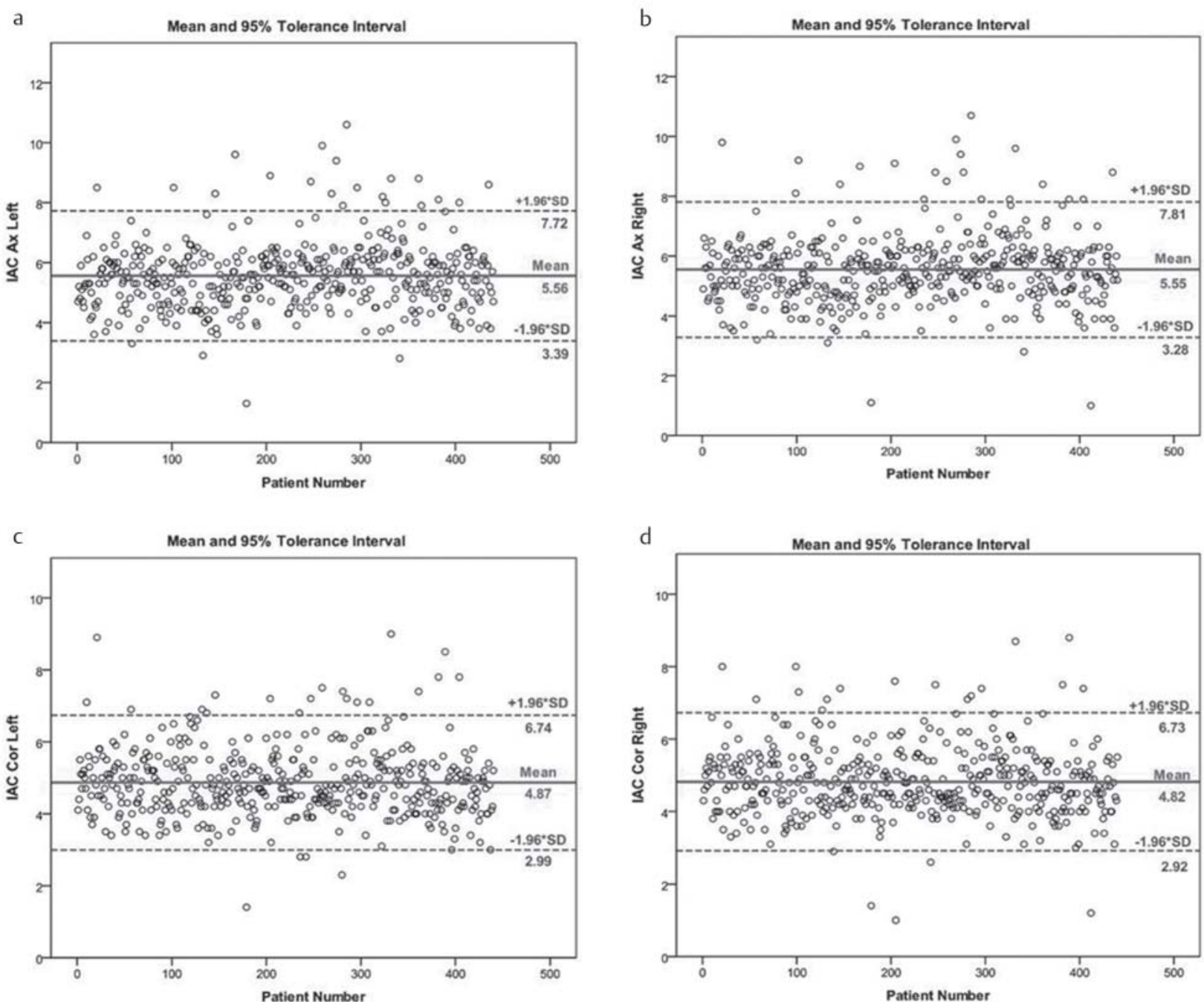

Fig. 1 Mean, $95 \%$ tolerance interval and distribution of IAC diameter in axial plane, left side $\mathbf{a}$, axial plane, right side $\mathbf{b}$, coronal plane, left side $\mathbf{c}$ and coronal plane, right side $\mathbf{d}$.

Abb. 1 Mittelwert, $95 \%$ Toleranzintervall und Verteilung des IAC-Durchmessers in axialer Ebene links a, axialer Ebene rechts b, koronarer Ebene links c und koronarer Ebene rechts $\mathbf{d}$. 
The normal range of IAC diameter proved to be smaller compared with Valvassori's tomographic X-ray studies, and the better precision of HR-CT-data is the presumable reason.

The diameter of the IAC in the axial plane is on average $0.7 \mathrm{~mm}$ wider than the diameter in the coronal plane ( $\bullet$ Fig. 2 c, d). In the regression analysis the ratio of the axial and coronal IAC diameter is 1.14, describing the normal oval shape of the IAC. The correlation of different measurement methods depicted in the Bland-Altman plot is close ( $\bullet$ Fig. 3a, b).

416 of 440 patients showed a normal IAC, whereas 20 cases presented enlargement and 4 cases stenosis of the IAC. IAC enlarge-

Table 2 Normal range for IAC-diameter in HR-CT (based on $95 \%$ confidence interval).

\begin{tabular}{|l|l|}
\hline axial, right & $3.3-7.8 \mathrm{~mm}$ \\
\hline axial, left & $3.4-7.7 \mathrm{~mm}$ \\
\hline coronal right & $2.9-6.7 \mathrm{~mm}$ \\
\hline coronal left & $3.0-6.7 \mathrm{~mm}$ \\
\hline
\end{tabular}

ment was found on both sides and in the axial and coronal plane in similar distribution.

It is clinically well known that high-grade IAC stenosis causes hearing disturbance but our group of patients provided no clear statistical approval because of its small number.

Two of these patients showed severe IAC stenosis and suffered from sensorineural hearing disturbance (as to be expected). Two other patients had a slight IAC stenosis. In one case this was an incidental finding after trauma, while the other patient showed dysplasia of the semicircular canal system.

In the group with a normal IAC diameter, we found the following clinical indications ( $\triangle$ Table 3 ).

In patients with IAC enlargement, hearing loss was the most important clinical indication (60\%). One patient (of 20) suffered from tinnitus, one from vertigo, facial paresis, trauma, cholesteatoma and otitis, and two had Franceschetti-Treacher-Collins syndrome.

However, in the case of IAC enlargement, the situation is complex: on the one hand the correlation between IAC enlargement and hearing loss or tinnitus and vertigo was not statistically
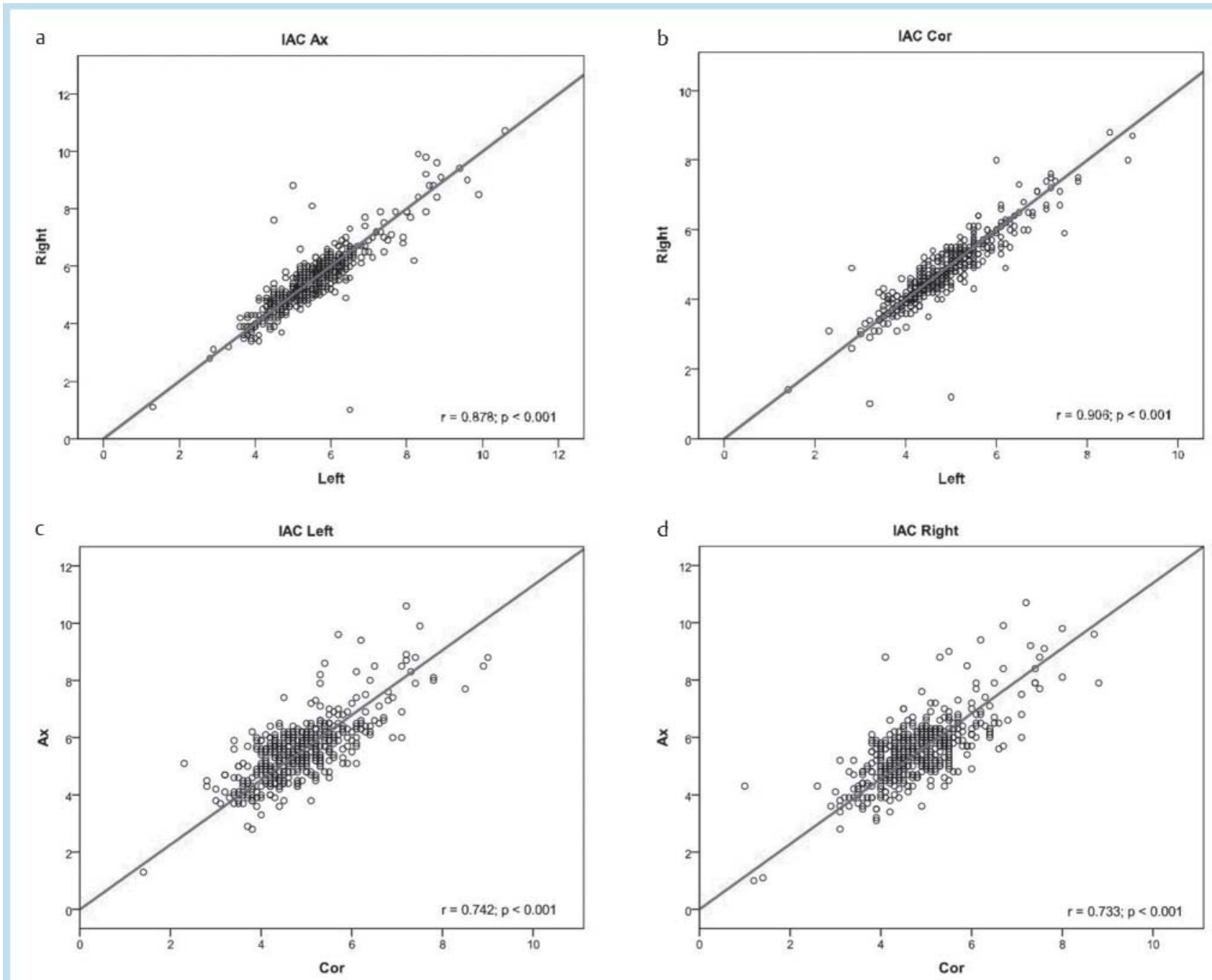

Fig. 2 a Graphic illustration of IAC symmetry in axial plane. b Graphic illustration of IAC symmetry in coronal plane. $\mathbf{c}$ Relation of axial and coronal IAC diameter on the left side. $\mathbf{d}$ Relation of axial and coronal IAC diameter on the right side.

Abb.2 a Graphische Darstellung der IAC-Symmetrie in axialer Ebene. b Graphische Darstellung der IAC-Symmetrie in koronarer Ebene. c Verhältnis von axialem und koronarem IAC-Durchmesser links. $\mathbf{d}$ Verhältnis von axialem und koronarem IAC-Durchmesser rechts. 
proven (despite the data listed above), while on the other hand it was striking that in nearly all patients with pronounced IAC enlargement (larger than $9 \mathrm{~mm}$ ) a clinical history of hearing loss or tinnitus and vertigo was present.

In some cases patients suffered from acute onset or progressive hearing loss, showing rapid clinical deterioration. In this group of patients convex-shaped margins of the IAC were often detected, appearing as an expansion from the cerebrospinal fluid (CSF) compartment.

The bony structure at the depth of the IAC, especially the IAC fundus near the basal turn of the cochlea and the vestibular labyrinth, is of special interest because of the close proximity of the CSF and perilymph space. In the group of patients with pronounced IAC enlargement (larger than $9 \mathrm{~mm}$ or mean plus three-fold SD), structural abnormalities of the IAC were found with thinning or defect of the bony partition between the CSF and perilymph. In our patients primarily the margin of the basal turn of the cochlea ( $\bullet$ Fig.4-6) and the vestibular labyrinth (๑ Fig. 7) was affected.

In detail, we found osseous anomalies at the fundus of the IAC in 8 persons. With one exception these patients belong to the group with IAC enlargement. Most of them showed a grossly enlarged IAC (more than $9 \mathrm{~mm}$ ). Bony fundus defects or pronounced thinning (appearing as a non-ossified thin membrane) affected the

Table 3 Clinical indications in the group with normal IAC diameter.

\begin{tabular}{|lc|}
\hline hearing loss & $39.6 \%$ \\
\hline inflammatory disease & $24.5 \%$ \\
\hline trauma & $12.0 \%$ \\
\hline cholesteatoma & $5.8 \%$ \\
\hline tumor & $5.3 \%$ \\
\hline vertigo & $5.0 \%$ \\
\hline malformation & $4.6 \%$ \\
\hline otosclerosis & $1.2 \%$ \\
\hline tinnitus & $1 \%$ \\
\hline facial nerve paresis & $1 \%$ \\
\hline
\end{tabular}

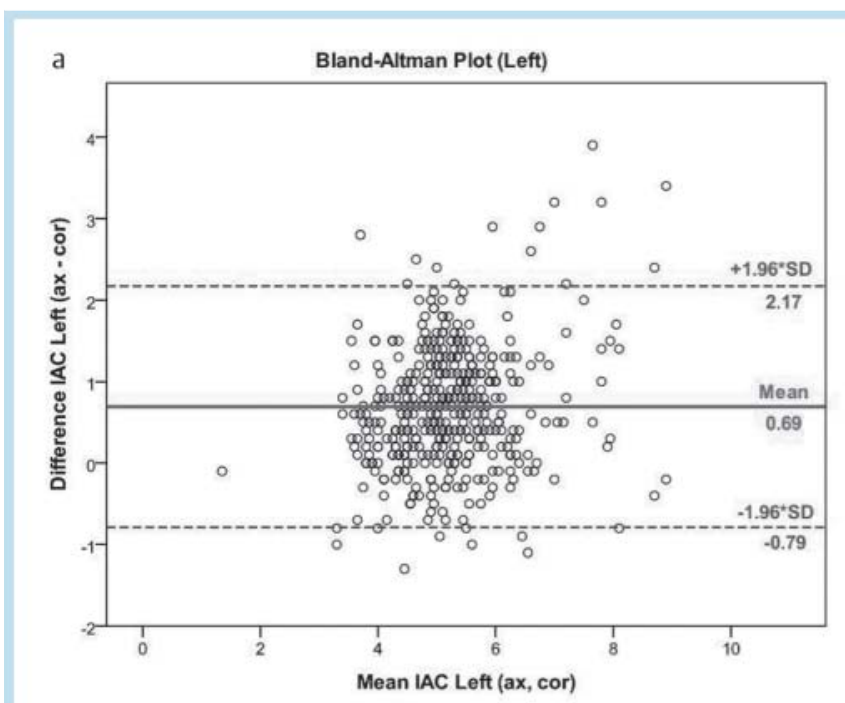

wall of the vestibular labyrinth in 2 cases and the margin of the basal turn of the cochlea in 6 cases. In $50 \%$ of cases the lesions were bilateral. Seven of these patients suffered from deafness or severe sensorineural hearing loss, while the eighth patient complained of intense pressure deep within both ears.

Because of the subtle anatomical structures, measurement or statistical evaluation of these findings is difficult, but frequency and clinical context are striking and a pathomechanism at the CSF perilymph border can be presumed.

\section{Discussion}

Already in the $1960 \mathrm{~s}$ Valvassori examined the configuration and diameter of the IAC using data from conventional X-ray tomography [17]. He described a large variation in diameter (in the coronal plane) with a normal range of 2 to $9 \mathrm{~mm}$. A side difference in the coronal diameter of more than 2 millimeters was regarded as pathologic.

In a CT-based study from 1995, Valvassori emphasizes again the high interindividual IAC variability with a normal range of the diameter of $2-12 \mathrm{~mm}[2,17]$.

As a new result, we found in our multislice CT study that the variability of the IAC diameter in the axial and coronal plane is much smaller compared with the publications by Valvassori. This finding supported by the high conformity of data on both sides leads to the question of the pathologic significance of large IAC diameters.

There is not a lot of information in the related literature about the development and clinical relevance of non-tumorous IAC enlargement.

Weinberg et al. described unilateral non-tumorous IAC enlargement in clinically asymptomatic persons already in the pre-CT era. An intact crista falciformis and absent cortical destruction led to the interpretation of a developmental anomaly. Already in the era of conventional X-ray tomography, Weinberg differentiated between constitutional IAC enlargement and the mostly

Fig. 3 a Bland-Altman plot (left side): Difference of axial and coronal IAC diameter vs. IAC mean (axial and coronal). b Bland-Altman plot (right side): Difference of axial and coronal IAC diameter vs. IAC mean (axial and coronal).

Abb. 3 a Bland-Altmann Plot links: Differenz von axialem und koronarem IAC-Durchmesser vs. IAC-Mittelwert (axial und koronar). b Bland-Altmann Plot rechts: Differenz von axialem und koronarem IAC-Durchmesser vs. IAC-Mittelwert (axial und koronar). 

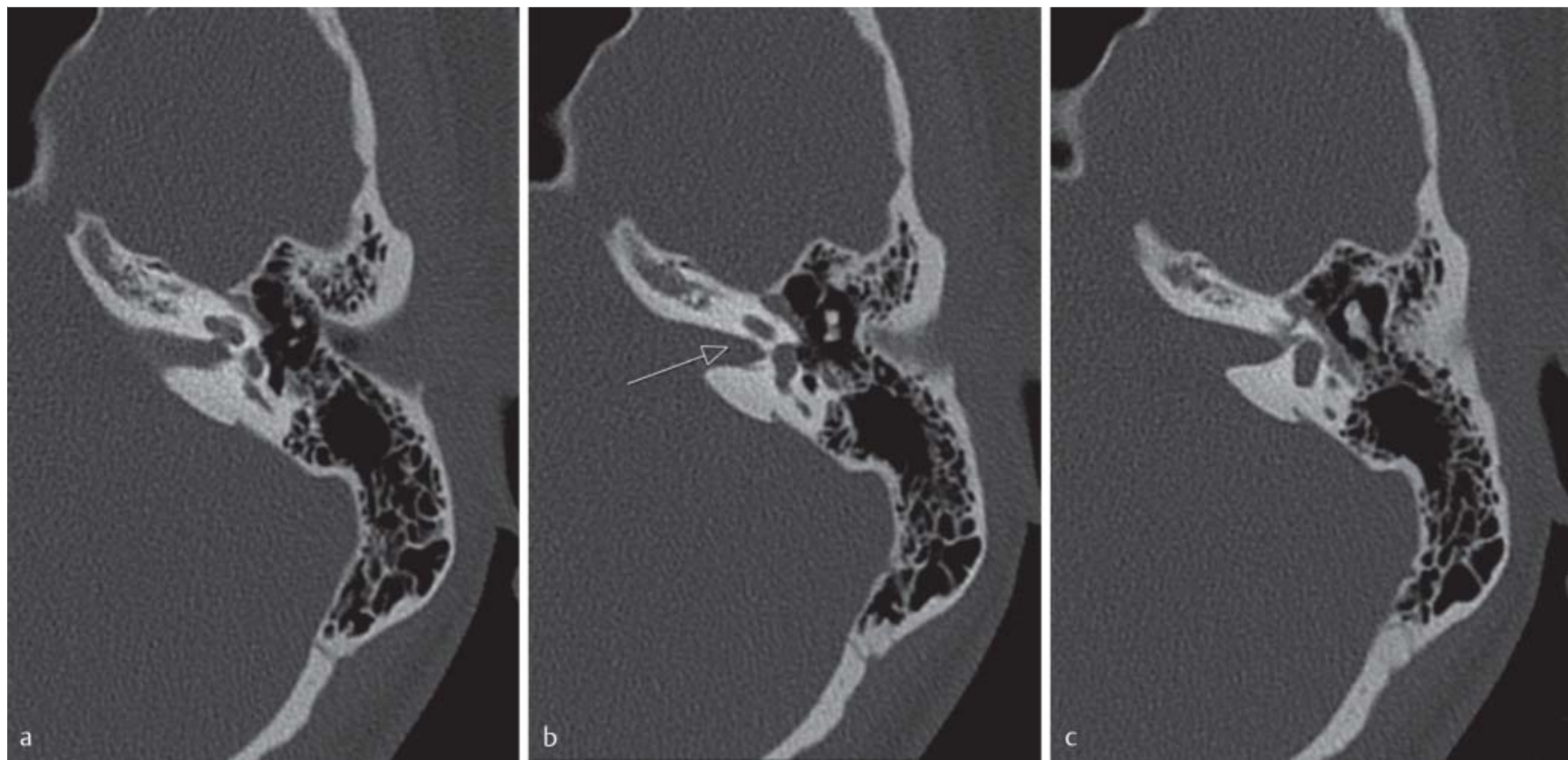

Fig. 4 a-c HR-CT of the temporal bone, axial plane, left side. Normal fundus of the internal auditory canal (arrow). Clear demarcation of the basal turn of the cochlea and the vestibulum labyrinthi.

Abb.4 a-c HR-CT des Felsenbeins, axial, links. Normaler Fundus des inneren Gehörganges (Pfeil). Klare Abgrenzbarkeit der basalen Cochlea-Windung und des Vestibulum labyrinthi.
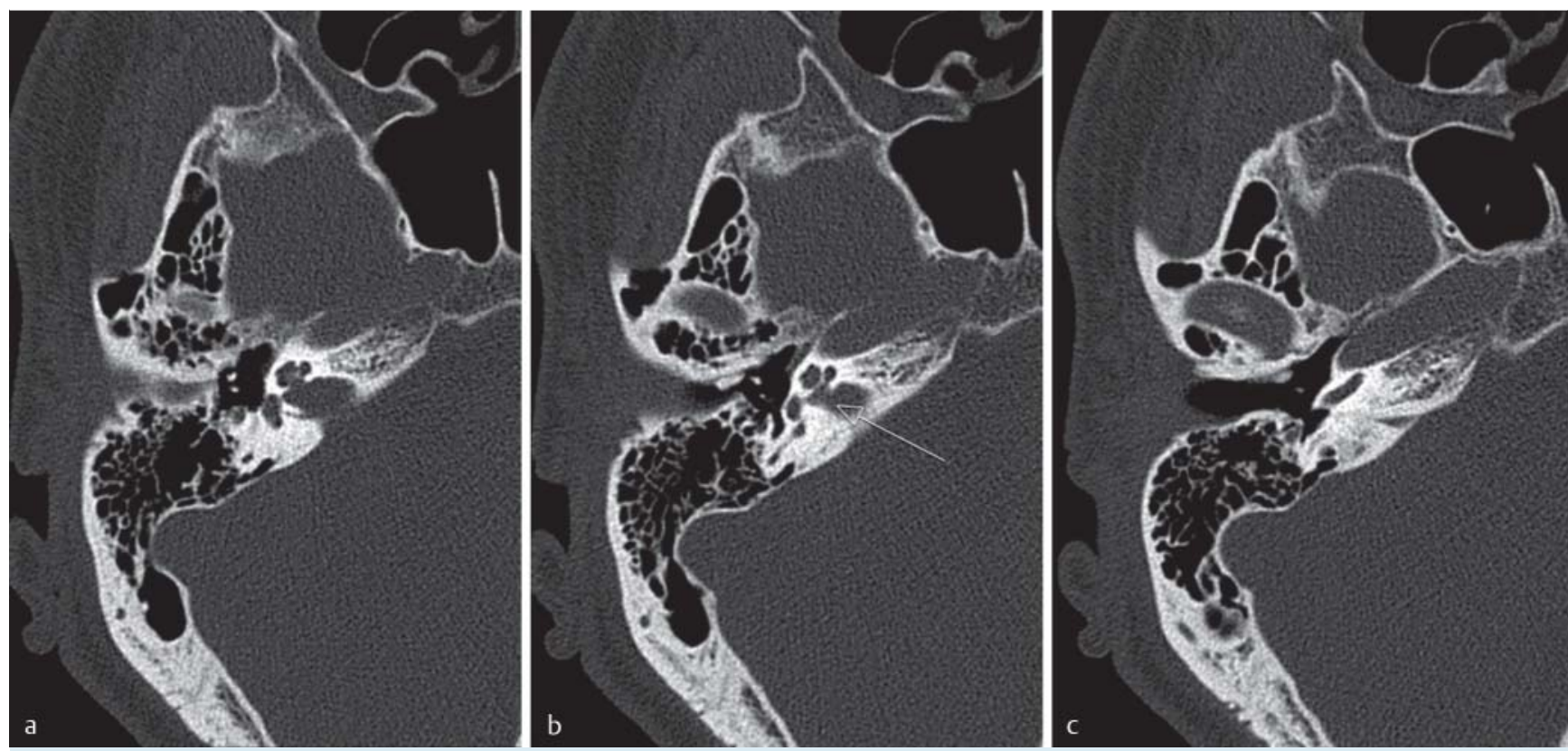

Fig. 5 a-c HR-CT of the temporal bone, axial plane, right side. Osseous defect (arrow) causing broad communication between the widened IAC fundus in the lower portion and the basal turn of the cochlea. Progressive and severe combined hearing loss.

Abb. 5 a - c HR-CT des Felsenbeines, axial, rechts. Knöcherner Defekt (Pfeil) mit breiter Kommunikation zwischen dem erweiterten IAC-Fundus im unteren Anteil und der basalen Cochlea-Windung. Schwere, fortschreitende kombinierte Schwerhörigkeit.

bilateral patulous internal auditory canal which is characterized by an increased height in the middle of the IAC in contrast to the enlargement of the posterior IAC in the developmental variant [14].

In 2003 Migirov analyzed the frequency and clinical relevance of the patulous IAC using a large number of high-resolution CT scans. This anomaly was found only in 2 of 645 cases $(=0.3 \%)$.
The author could not find a clear association between clinical symptoms and radiological findings, and sensorineural hearing loss in particular was not found. The author refers to the normal range of IAC diameters published by Valvassori and does not present any further results about other types of IAC enlargement or bony anomalies at the IAC fundus. In summary, patulous IAC was classified as a variant without clinical relevance [16]. 

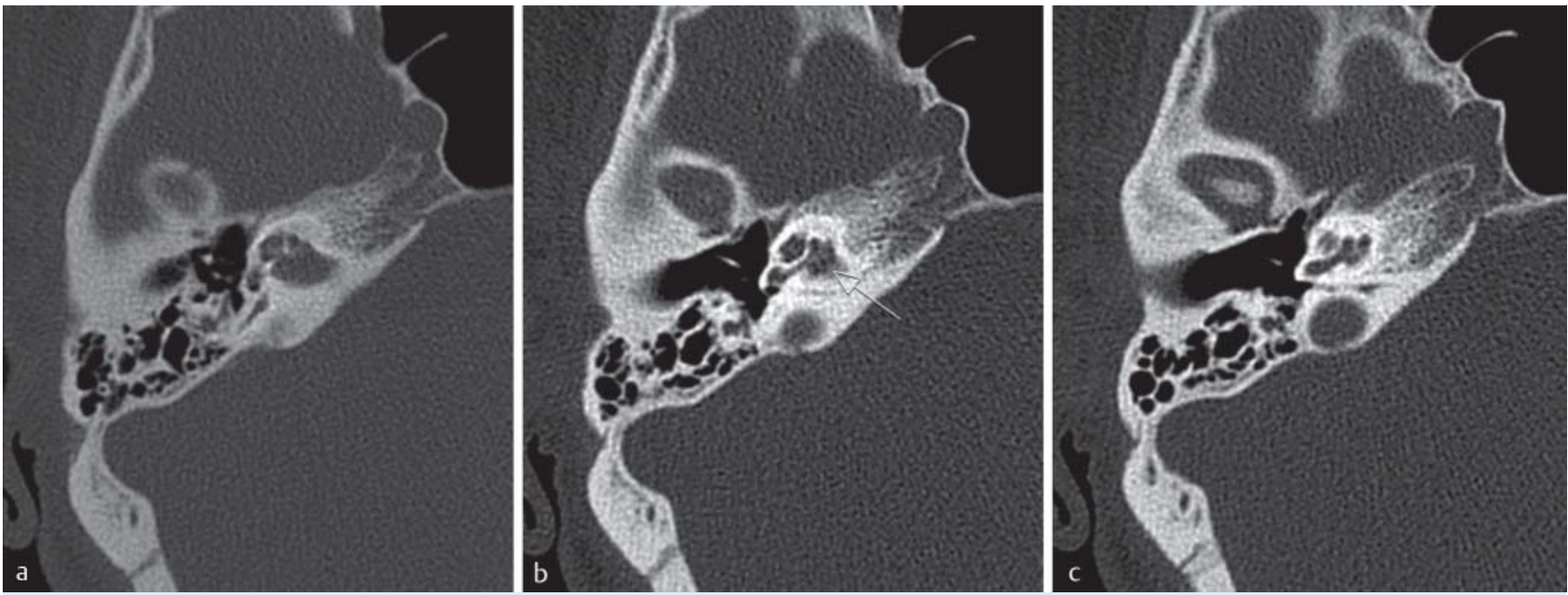

Fig. 6 a-c HR-CT of the temporal bone, axial plane, right side. Bony defect immediately below the cochlear nerve entry reaching the basal turn of the cochlea (arrow). Acute onset hearing loss and tinnitus.

Abb. 6 a-c cHR-CT des Felsenbeines, axial, rechts. Knöcherner Defekt unmittelbar unterhalb des Cochlearnerveneintrittes mit Erreichen der basalen CochleaWindung. Akut aufgetretener Hörverlust und Tinnitus.
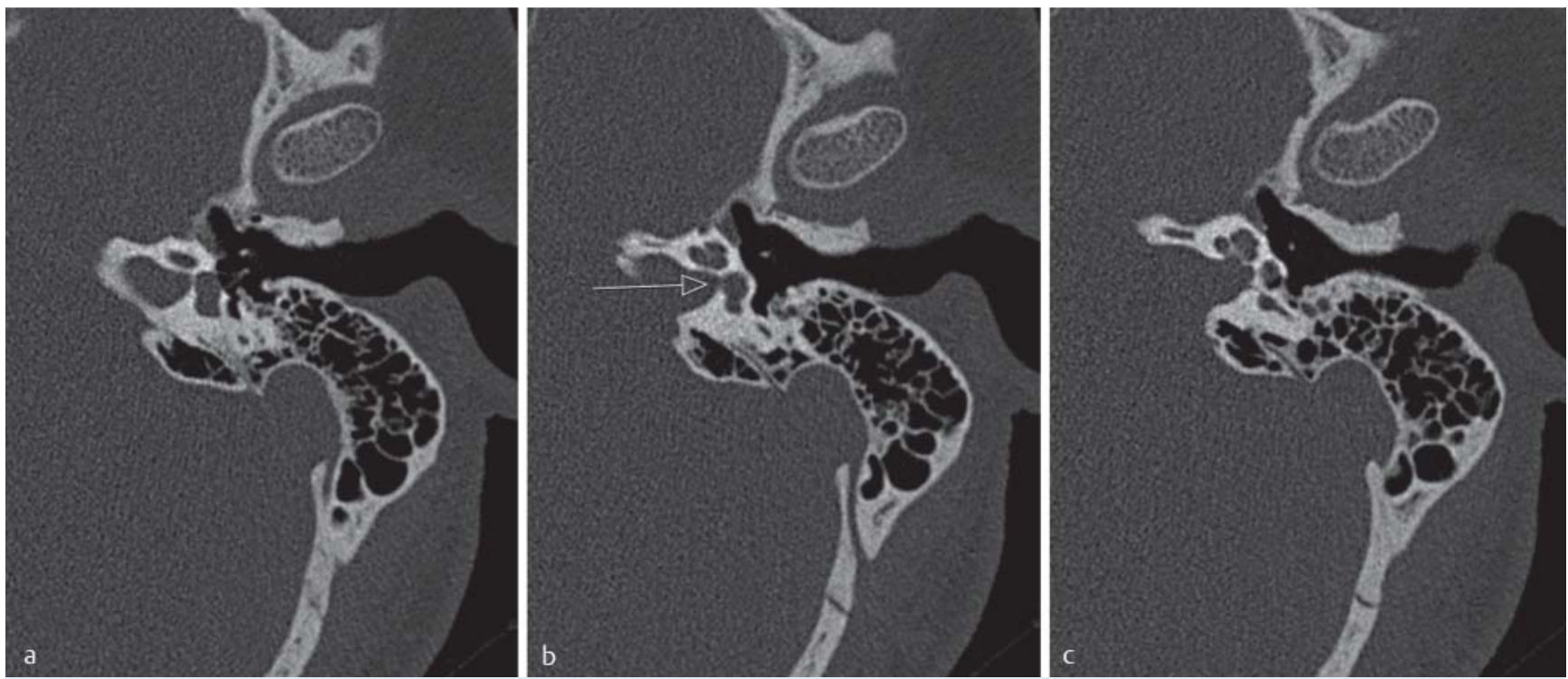

Fig. 7 a-c HR-CT of the temporal bone, axial plane, left side. Abnormal communication between the enlarged internal auditory canal and the vestibulum labyrinthi (arrow). Sensorineural hearing loss and tinnitus.

Abb. 7 a-c HR-CT des Felsenbeines, axial, links. Abnorme Kommunikation zwischen dem erweiterten inneren Gehörgang und dem Vestibulum labyrinthi (Pfeil). Sensorineuraler Hörverlust und Tinnitus.

On the other hand, there is some evidence in the sparse collection of related literature that IAC enlargement could be of clinical relevance with effects on inner ear function and also sound conduction.

Swartz and Harnsberger presented a patient showing wide bilateral internal auditory canals without any evidence of abnormal intrameatal enhancement who suffered from sensorineural hearing loss that began very early in life [18]. This finding was classified as a "striking developmental variation". The authors underline the importance of the bony structures in the inner portion of the IAC. The bony partition between the fundus of the internal auditory canal and the basal turn of the cochlea and vestibular labyrinth is of great relevance as a barrier between the subarachnoid space and the perilymph space of the inner ear. A fistula in this region causes pathologic communication between these compartments and transmission of intracranial pressure to the perilymph space.

In our study we found a group of patients $(n=11)$ with pronounced dilatation of the internal auditory canal, defined as the mean value plus threefold standard deviation. Even though the number of cases is relatively small and with limited statistical significance, it is remarkable that all of the patients with an extraordinarily wide internal auditory canal suffered from hearing impairment (about $90 \%$ !) or other inner ear symptoms like vertigo and tinnitus. Most of the patients with hearing disturbance showed sensorineural hearing loss $(n=7)$, whereas the others 
showed mixed or conductive hearing loss $(n=3)$ (see also discussion below). Furthermore, in some of these patients, we found structural bone anomalies at the IAC fundus such as thinning, irregularity or defect of the bony partition between the IAC and inner ear ( $\bullet$ Fig. 5-7). Only a small collection of literature exists about such findings, the majority of which deals with the inherited X-linked deafness syndrome. These patients suffer from a mixed hearing deficit due to defective bony partition at the IAC fundus.

In these patients a clear correlation between mixed hearing deficit and IAC enlargement was recognized. The syndrome of X-linked progressive mixed deafness (with perilymphatic gusher during stapes surgery) was first described in 1974. The bulbous enlargement of the internal auditory canal, typically located in the lateral portion of the IAC fundus, was depicted already in the $1970 \mathrm{~s}$ in conventional coronal polytomographic examinations [19]. Another typical finding is an osseous defect in the bony partition between the IAC and the perilymph space of the inner ear near the basal turn of the cochlea [20]. Normally, in healthy subjects, the lateral end of the IAC is comprised of a subtle bony plate (lamina cribrosa). This membranous bony structure is penetrated by the vestibular nerves, the facial nerve and the small branches of the cochlear nerve running from the spiral ganglion to the cochlear end organs [19]. The bony plate and the spiral ganglion separate the subarachnoid space in the IAC from the perilymph space. The bony defect in this partition is the reason for perilymph hydrops and "stapes gusher" during stapes surgery [21 - 23].

We cannot completely rule out that some of our IAC enlargement patients could suffer from this inherited syndrome, but in our cases usually not only the lateral part of the IAC is affected. Furthermore, we did not find typical facial canal widening (both morphological criteria for X-linked deafness syndrome).

Nevertheless, our results suggest that IAC enlargement and lesions of the bony partition at the IAC fundus are relevant not only in rare conditions such as X-linked deafness syndrome. A few reports in related publications support this hypothesis and describe impairment of inner ear function and also sound transmission.

Phelps discussed the possible consequences of subarachnoidperilymph fistula. In his study he analyzed 20 patients suffering from dysplasia of the inner ear, in particular of the basal turn of the cochlea leading to communication between the subarachnoid space and the middle ear with the resulting risk of ascending meningitis and anacusis [24].

A remarkable case report from 2010 describes a young patient with bilateral IAC enlargement who developed acute sensorineural hearing loss following physical exercise (weight lifting). The patient first complained about left-sided hearing loss. Symptoms did not resolve after steroid and antiviral drug therapy. Following another session of exercise, he developed sudden hearing loss on the other side. Vestibular symptoms did not occur [25]. This indicates that the border zone between IAC fundus and the perilymph space of the inner ear seems to have more pathophysiologic relevance than previously supposed. In addition to the cochlear and vestibular aqueduct, the internal auditory canal is one of the three communication channels between the intracranial space and the inner ear [26]. If these communication routes are patent, the cerebrospinal fluid provides the reference pressure for the perilymph and to a large extent also for the endolymph, as Reissner`s membrane can only withstand a relatively small pressure gradient [27]. Intracochlear pressure, influenced by the CSF pressure, in turn has an impact on the sound transmis- sion system of the middle ear. Increased pressure in the perilymph, conducted from the CSF in the case of fistulous communication, causes elevation of cochlear impedance. In this way abnormal pressure transmission to the perilymph can also induce conductive hearing impairment [28 - 30].

\section{Conclusion \\ $\nabla$}

The presented study allows a CT-based definition of normal shape and size of the internal auditory canal. It is based on a large number of high-resolution multislice CT examinations. Compared with previous conventional X-ray studies, the variability of IAC diameter proved to be smaller and enlargement of the internal auditory canal in nearly $5 \%$ of cases was obviously not uncommon. Moreover, our examination suggests that pronounced IAC enlargement could be a risk factor for acute or chronic progressive sensorineural or combined hearing loss. In these patients the osseous structures in the IAC fundus are of special interest, where frequent defects, irregularity or at least thinning of the bony partition in the proximity of the basal turn of the cochlea or vestibulum was found. This supports the hypothesis of pathologic pressure transmission from the CSF to the perilymph space. HR computed tomography plays a major role in detecting this possibly underestimated reason for sensorineural or even combined hearing loss. The examining otologist and the radiologist should not only consider it in the occurrence of IAC enlargement but also perform careful analysis of the osseous structures in the CSF perilymph border zone.

\section{Clinical relevance:}

- Compared with previous conventional X-ray studies, the variability of IAC diameter proved to be smaller, and enlargement of the internal auditory canal in nearly $5 \%$ of cases was not uncommon.

- Pronounced IAC enlargement seems to be a risk factor for acute or chronic sensorineural or combined hearing loss.

- In patients with marked IAC enlargement, frequently defects, irregularity or at least thinning of the bony partition between the IAC fundus and inner ear structures was found.

\section{References}

1 Valvassori GE, Potter GD, Hanafee WN et al. Radiology of the Ear, Nose and Throat. Stuttgart, New York: Thieme; 1982: 96-98

2 Valvassori GE. The internal auditory canal revisited. The high definition approach. Otolaryngol Clin North Am 1995; 28: 431-511

3 Duvoisin B, Fernandes J, Doyon D et al. Magnetic resonance findings in 92 acoustic neuromas. Eur J Radiol 1991; 13: 96 - 102

4 Salzmann KL, Davidson HC, Harnsberger HR et al. Dumbbell schwannomas of the internal auditory canal. Am J Neuroradiol 2001; 22: 1368 1376

5 Tsunoda A, Komatsuzzaki A, Suzuki Y et al. Three dimensional imaging of the internal auditory canal in patients with acoustic neuroma. Acta Otolaryngol Suppl 2000; 542: 6-8

6 Ueyama T, Tamaki N, Kondoh $T$ et al. Cerebellopontine angle ependymoma with internal auditory canal enlargement and pineal extension - case report. Neurol Med. Chir 1997; 37: 762 - 765

7 Samii M, Nakamura M, Mirzai S et al. Cavernous angiomas within the auditory canal. J Neurosurg 2008; 105: $581-587$

8 Aquilina K, Nanra JS, Brett F et al. Cavernous angioma of the internal auditory canal. J Laryngol Otol 2004; 118: 368-371 
9 Fleck SK, BaldaufJ, Langner S et al. Arachnoid cyst confined to the internal auditory canal - endoscope-assisted resection: case report and review of the literature. Neurosurgery 2011; 68: E267-E270

10 Kitamura K, Senba T, Komatsuzaki A. Bilateral internal auditory canal enlargement without acoustic nerve tumor in von Recklinghausen neurofibromatosis. Neurofibromatosis 1989; 2: 47-52

11 Propst EJ, Blaser S, Gordon KA et al. Temporal bone findings on computed tomography imaging in branchio-oto-renal syndrome. Laryngoscope 2005; 115: $1855-1862$

12 Crain MR, Dolan KD. Internal auditory canal enlargement in Paget's disease appearing as bilateral acoustic neuromas. Ann Otol Rhinol Laryngol 2005; 99: 833-834

13 Blaser S, Propst EJ, Martin D et al. Inner ear dysplasia is common in children with Down syndrome (trisomy 21). Laryngoscope 2006; 116: $2113-2119$

14 Weinberg PE, Kim KS, Gore RM. Unilateral enlargement of the internal auditory canal: a developmental variant. Surg Neurol 1981; 15: 39-42

15 Kokai H, Oohashi M, Ishikawa K et al. Clinical review of inner ear malformation. Nippon Jibinkoka Gakkai Kalho 2003; 106: 1038-1044

16 Migirov L. Patulous internal auditory canal. Acta Otolaryngol Head Neck Surg 2003; 129: 992 -993

17 Valvassori G. The radiological diagnosis of acoustic neuromas. Arch Otolaryng 1966; 83: 92 - 97

18 Swartz JD, Harnsberger HR. The otic capsules and otodystrophies. Swartz JD. Harnsberger HR. In: (eds) Imaging of the temporal bone. New York Stuttgart: Thieme; 1998: 240-317

19 Phelps PD, Reardon W, Pembrey $M$ et al. X-linked deafness, stapes gusher and a distinctive defect of the inner ear. Neuroradiology 1990; 33 : $326-330$
20 Kumar G, Castillo M, Buchmann CA. X-linked stapes gusher: CT findings in one patient. Am J Neuroradiol 2003; 24: 1130-1132

21 Papadaki E, Prassopoulos P, Bizakis J et al. X-linked deafness with stapes gusher in females. Eur J Radiol 1998; 29: 71-75

22 Cremers CW, Huygen PL. Clinical features of female heterozygotes in the $\mathrm{x}$-linked mixed deafness syndrome (with perilymphatic gusher during stapes surgery). Int J Pediatr Otorhinolaryngol 1983; 6: 179-185

23 Cremers CW. Audiologic features of the X-linked progressive mixed deafness syndrome with perilymphatic gusher during stapes surgery. Am J Otol 1985; 6: 243-246

24 Phelps PD, King A, Michaels L. Cochlear dysplasia and meningitis. Am J Otol 1994; 15: $551-557$

25 Magliulo G, Stasolla A, Collichio MG et al. Enlarged internal auditory canal and sudden deafness. J Laryngol Otol 2010; 124: 931 - 933

26 Ciuman RR. Communication routes between intracranial spaces and inner ear function, pathophysiologic importance and relations with inner ear disease. Am J Otolaryngol 2009; 30: 193 - 202

27 Marchbanks RJ, Reid A. Cochlear and cerebrospinal fluid pressure: their interrelationship and control mechanisms. Br J Audiol 1990; 24: $179-187$

28 Marchbanks RJ, Reid A, Martin AM et al. The effect of raised intracrania pressure on intracochlear fluid pressure: three case studies. Br J Audiol 1987; 21: $127-130$

29 Masaaki K, Mikio S, Akira K. Equilibrium of inner and middle ear pressure. Acta Otolaryngol Suppl 1994; 510: $113-115$

30 Murakami S, Gyo K, Goode RL. Effect of increased inner ear pressure on middle ear mechanics. Otolaryngol Head Neck Surg 1998; 118 : $703-708$ 